\title{
Revisión de la cosa juzgada írrita
}

\section{Arodín Valcarce}

«La renuncia consciente de la verdad es incompatible con el servicio de justicia».

$$
\text { (CSJN en L.L., v. 89, p. 412) }
$$

Los vicios de la actividad pueden afectar no sólo a los actos procesales aislados, sino también a todo un proceso, de suerte que en determinados supuestos será procedente la declaración de nulidad de un proceso íntegro ${ }^{1}$.

No se trata de que las formas procesales hayan sido perturbadas. El procedimiento luce pleno de regularidad, y el órgano jurisdiccional ha cumplido ostensiblemente su cometido, pero tales situaciones se plantean generalmente cuando median vicios sustanciales intrínsecos, distintos de las irregularidades extrínsecas. Mientras éstas apuntan a la violación de las formas estatuidas, aquéllos se repliegan en los casos en que sin escozor del ritual «el vicio está en la entraña».

Así, el proceso fraudulento no es sino un negocio fraudulento, realizado con o mediante instrumentos procesales; el fraude y la simulación a través del proceso están orquestados por las partes, pero también dirigidos al juez a quien enlazan para complicarlo en la expedición de una sentencia injusta. El juez, sujeto también de la relación procesal, ha sido llevado a engaño en la confección de un acto que de lícito sólo

1 Roberto O. Berizonce. "Cosa Juzgada Fraudulenta» en JUS Revista Jurídica de la Provincia de Buenos Aires, N 10, p. 76. 
tiene lo externo. Y si por principio de orden común es anulable todo acto jurídico con vicio de error, parece indudable que la sentencia obtenida en esas condiciones deba asimismo caer bajo las consecuencias de esta sanción ${ }^{2}$.

«El fraude procesal es toda maniobra de las partes, de los terceros, del juez o de sus auxiliares que tienda a obtener o dictar una sentencia con o sin valor de cosa juzgada, o la homologación de un acuerdo procesal u otra resolución judicial, con fines ilícitos o a impedir su pronunciamiento o ejecución $»^{3}$.

Así, si las partes, para lograr la sentencia acogedora de sus ilegítimas pretensiones, han recurrido, por ejemplo a testigos comprometidos a falsear los hechos, o se hubieren servido de documentos adulterados o del cohecho de peritos, tal comportamiento asume el rol de una asechanza dirigida a inducir en error al juez, según es, precisamente la noción del dolo. Víctima inmediata del dolo es, pues, la propia administración de justicia, en la persona del juez que la representa.

Es evidente que en estos casos, la presunción de justicia que cubre la decisión pasada en autoridad de cosa juzgada ha de ceder ante el fraude demostrado. Es inoponible el resultado de un proceso obtenido con escarnio de principios fundamentales, y tanto los terceros perjudicados como las propias partes pueden valerse de la acción de la nulidad. Esa es la posición dominante de la doctrina y de la jurisprudencia.

También procede la revisión de la cosa juzgada en casos en que no habría mediado fraude, así ocurre por ejemplo, si después de pronunciada la sentencia definitiva la parte perjudicada obtuviere documentos decisivos o ignorados o extraviados que pueden hacer variar la sentencia definitiva cuya revisión se pretende $e^{4}$.

Colocados ante la alternativa de elegir entre la seguridad jurídica que emerge de la cosa juzgada, aun en oportunidades, a costa de la

2 Axel M. Bremberg. «La cosa juzgada y daño de terceros», L.L. Tomo. 79, p. 389.

3 Jorge W. Peyrano. El Proceso Civil. Ed. Astrea, 1978, p. 202.

4 Arts. $156^{\circ}$ inc. 1 CPC y $144^{\circ}$ inc. 9 de la Constitución de Mendoza; Art. $395^{\circ}$ inc. 3 CPCC Pcia. de Córdoba; Art. 283 Código General del Proceso del Uruguay. 
justicia, por un lado, y la justicia, aun a veces, a costa de la seguridad jurídica, por otro, tanto estudiosos del derecho, por una parte, como jueces por otra, se inclinan en casos extremos, muy especiales y siempre con carácter excepcional, por la justicia, valor supremo éste que no debe ser dejado a un costado ${ }^{5}$.

\section{Antecedentes jurisprudenciales}

La Corte Suprema de Justicia de la nación sentó la doctrina favorable a la revisión de las sentencias pasadas en autoridad de cosa juzgada en los casos «Villareal de Rodríguez, Manuela v. Onetto, Domingo C.», 5/ $6 / 57^{6}$; «Tibold, José y otros", 23/11/627; "Campbell Davidson, Juan v.

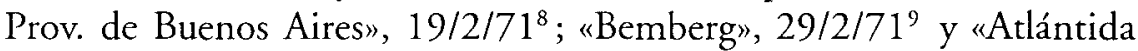
S.R.L. v. Naveira, José Antonio", 26/6/72 10

El paradigma lo constituye el caso «Campbell Davidson» donde el Alto Tribunal dijo: «son revisables las sentencias fraudulentas o dictadas en virtud de cohecho, violencia $u$ otra maquinación [...]. No puede reconocerse eficacia final a la sentencia dictada en juicio en que se ha incurrido en estafa procesal. La institución de la cosa juzgada, como todas las instituciones legales, debe organizarse sobre bases compatibles con los derechos y garantías constitucionales. No a toda sentencia judicial puede reconocérsele fuerza de resolución inmutable, sino sólo a aquéllas que han sido precedidas de un proceso contradictorio en que el vencido haya tenido adecuada y sustancial oportunidad de audiencia y prueba. No puede invocarse el principio de inmutabilidad de la cosa juzgada cuando no ha existido un auténtico y verdadero proceso judicial».

La Corte Suprema de Justicia de la Nación en los autos «Recurso de hecho deducido por la demandada en la causa Duart, Víctor c/ Banco

5 Del voto del Dr. Bossi, en autos Lambruschini, Sara Baldomera c/Corbani de Canavesi, Nélida s/Reivindicación y Nulidad del Acto Jurídico, Cám. $2^{\circ}$ de Apelación - Sala III, La Plata, 23/5/67.

6 Fallos 238-18 y JA 1957-IV-263.

7 Fallos 254-320 y JA 1963-I-674.

8 Fallos 279-54 y JA 11-1971-231.

9 Fallos 281-421.

10 Fallos 283-66 y JA 16-1972-95. 
Central de la República Argentina», en sus considerandos sostuvo que «[...] si bien es cierto que conocida jurisprudencia de este Tribunal confirió jerarquía constitucional a la cosa juzgada, en razón de que la inalterabilidad de los derechos definitivamente adquiridos por sentencia firme reconoce fundamento en los derechos de propiedad y defensa en juicio y que la estabilidad de las decisiones jurisdiccionales constituye un presupuesto ineludible para la seguridad jurídica, no lo es menos que también se han reconocido numerosas excepciones, entre otros supuestos, en los casos de estafa procesal, ya que debe admitirse, en tales hipótesis, que la existencia de resoluciones que formalmente se apartan de lo dispuesto en una sentencia firme «lejos de menoscabar la autoridad de la cosa juzgada la salvaguardan, porque salvaguardan su justicia, sin la cual el más íntimo sentido de dicha autoridad, que es su sentido moral, no es concebible» (Fallos : 310: 1797 y sus citas del considerando $7^{\circ}$, segundo párrafo, el entrecomillado corresponde a Fallos: 294: 434) (Considerando 40 ). Que «[...] esta Corte ha sostenido que la admisión genérica, en el ordenamiento jurídico argentino, de la institución de la cosa juzgada, no significa que no pueda condicionarse su reconocimiento a la inexistencia de dolo en la causa en que se ha expedido la sentencia, ya que «la circunstancia que de ésta manera se afecte la seguridad propia de las sentencias firmes en el orden civil, debe ceder a la razón de justicia, que exige que el delito comprobado no rinda beneficios" (Fallos: 254:320, doctrina reiterada en Fallos: 275:389; 279:137 y 283:66) (Considerando 7o). Que «[...] la interpretación de normas procesales no puede prevalecer sobre la primacía que corresponde atribuir a la búsqueda del esclarecimiento de la verdad jurídica objetiva, cuyo desconocimiento consciente es incompatible con el adecuado servicio de justicia que asegura el Art. $18^{\circ}$ de la Constitución nacional $[. . .]_{»}$ (Considerando $6^{\circ}$ ) (Fallos de la Corte Suprema: 320 pp. 1038 a 1041).

\section{Requisitos de viabilidad}

Teniendo en cuenta la doctrina y jurisprudencia que admiten la revisión de la cosa juzgada, en principio, podemos decir que los recaudos para que la pretensión en tratamiento pueda prosperar son los siguientes: 
a. sentencia definitiva pasada en autoridad de cosa juzgada;

b. que aquella adolezca de vicios esenciales, preponderantes, sustanciales;

c. existencia de un daño al pretensor;

d. causalidad adecuada;

e. interés actual en la declaración de nulidad;

f. que el afectado haya ejercitado los remedios legales que, por vía indirecta, eran capaces de remover el vicio esencial del que luego se muestra quejoso.

\section{Conveniencia de legislar}

No existen inconvenientes para deducir la revisión de la cosa juzgada fraudulenta no obstante la circunstancia de que la ley procesal no legisle expresamente sobre esa vía autónoma.

Son garantías constitucionales las que sostienen la imposibilidad de consagrar el proceso fraudulento. Así como la sentencia arbitraria contiene inconstitucionalidad en el decisorio, el proceso viciado intrínsecamente no admite alcanzar el grado de sentencia inmutable cuando no está precedido de un «auténtico y verdadero proceso judicial» ${ }^{11}$.

Adolfo E. Parry sostiene: «la expresión cosa juzgada no equivale a decisión definitiva o inapelable -como erróneamente suele creerse-, pues solamente hay cosa juzgada cuando ha habido contienda promovida por la lesión de un derecho o de un interés legítimo, y la decisión a la cual la cosa juzgada se refiere ha sido dictada en virtud de "procedimiento regular", con garantías de defensa, audiencia, prueba y alegación [...] La circunstancia de que ningún texto legal autorice expresamente la acción revocatoria no constituye impedimento para su admisibilidad. Para reconocer su procedencia basta con acudir a la vasta teoría que recuerda que ciertos principios generales del derecho no necesitan formulación expresa porque son del derecho mismo; sin ellos no habría igualdad, ni seguridad, ni justicia. La consagración del fraude es el desprestigio máximo y la negación del derecho, fuente incesante de descontento en el pueblo y burla de la ley» ${ }^{12}$.

11 Osvaldo A. Gozaíni. La conducta en el Proceso. Ed. LEP, 1988, p. 278.

12 Adolfo E. Parry. «La Cosa Juzgada Irrita». L.L., vol. 82, p. 473. 
De todas maneras, algunos autores como Ibáñez y Frocham, sostienen que el instituto de la revisión no prestigia la cosa juzgada sino, por el contrario la debilita "con una amenaza de inseguridad que suspende el fin buscado en el proceso civil: la certeza en la declaración del derecho [...] el principio de la cosa juzgada "purga» toda nulidad. Si no alcanzare a cubrir el dolo o el fraude convertido dentro del proceso, será el legislador quien ha de decir si en el estado actual de nuestro derecho y de nuestras costumbres de pueblo sano, vale la pena recomenzar [...] y otorgar una acción ${ }^{13}$. Otros autores también sostienen la conveniencia de que se legisle sobre «la acción autónoma procesal de nulidad por vicios intrínsecos» $\rangle^{14}$.

Siguiendo a Peyrano, nos parece conveniente la adopción de una nueva terminología, «desviación procesal» en reemplazo de "fraude procesal, ${ }^{15}, y$ considerando las ventajas o desventajas de acuñar un texto abierto o numerativo de situaciones que harían admisible la acción, en trance de optar, preferimos la consagración de un texto abierto a las situaciones siempre nuevas, a condición de la utilización de un vocabulario que inequívocamente exprese el carácter excepcionalísimo de dicha vía.

\section{Recurso de revisión o acción autónoma de nulidad}

Tradicionalmente se ha caracterizado a la vía invalidatoria de la cosa juzgada como un «recurso», y así se lo ha regulado en algunas provincias argentinas - $\mathrm{CPC}$ de Mendoza (Art. 156 $6^{\circ}$, Corrientes (Art. 290 incs. 4, 5, 6 y 7), San Luis (Art. 548 ), Córdoba (Art. 395 ), San Juan (Art. $364^{\circ}$ ) - y en la legislación comparada -Uruguay (Código General del Proceso, Art. $281^{\circ}$ ), Chile, (CPC Art. $810^{\circ}$ )-, mas, como sostiene Hitters, esta calificación no resiste a la crítica, puesto que muy pocas de las notas principales de los procedimientos recursivos se dan

13 Tratado de los Recursos en el Proceso Civil, $3^{\circ}$ ed., Depalma, Buenos Aires, p. $570, N^{\circ} 374$ y 574.

14 Roberto O. Berizonce, op. cit., p. 77.

15 Peyrano, op. cit., p. 204. 
en la revisión, salvo la de llevar a cabo un examen de lo decidido por un Tribunal.

El citado autor, enuncia las siguientes diferencias entre los institutos de referencia:

1. La revisión va contra decisiones firmes, los recursos obviamente no.

2. La eficacia de éstos depende de que la resolución adolezca de vicios en relación con una determinada situación necesariamente precedente a la misma, o con una norma jurídica de vigencia igualmente anterior a la propia decisión. En cambio, en la revisión, los defectos que pueden dar lugar a la retractación han de ponerse de relieve en consonancia con situaciones fácticas conocidas con posterioridad al fallo que se pretende invalidar; mientras que jamás puede producirse por vicios de tipo jurídico.

3. Para recurrir sólo están legitimadas las partes que han sufrido el perjuicio, en tanto que la revisión puede ser solicitada también por los herederos y aún por los terceros afectados.

4. Los recursos generalmente tienen efecto suspensivo; la revisión, en principio no.

5. El juez que resuelve aquéllos tiene el mismo conocimiento e idénticos poderes que el a-quo, en tanto el que conoce de la revisión está limitado sea por la naturaleza del contralor que le es dable hacer o por la necesidad de una investigación previa de admisión ${ }^{16}$.

En nuestro país, doctrina y jurisprudencia aceptan la existencia de una acción autónoma de nulidad ${ }^{17}$ que supone una demanda que inicie un juicio de conocimiento pleno, el que debe transitar por todas las etapas e instancias, respetando los principios del debido proceso; la autoridad de la cosa juzgada, aun cuando en el caso fuese aparente, sólo puede destruirse mediante un debate adecuado ${ }^{18}$. Se la califica de autónoma porque genera una nueva instancia distinta en principio de la

16 Juan Carlos Hitters. Revisión de la Cosa Juzgada. Ed. LEP, 1977, pp 15-16.

17 Luis Alberto Maurino, "Revisión de la cosa juzgada. Acción autónoma de nulidad» en Revista del Derecho Procesal N², Ed. Rubinzal-Culzoni, 1999, p. 109.

18 Roland Arazi. «Acción de revisión de cosa juzgada irrita" en Revista del Derecho Procesal No 2, Ed. Rubinzal Culzoni, p. 384. 
que se intenta destruir ${ }^{19}$ no debiendo confundirse esta acción con la demanda de nulidad de los actos jurídicos privados -que tiene su actividad fuera del proceso-; con el juicio de conocimiento posterior al ejecutivo -por esta vía no pueden discutirse las interpretaciones legales formuladas en la sentencia ni la validez o nulidad del procedimiento de ejecución-; ni con el recurso de rescisión -en éste se cuestionan fundamentos y no requisitos formales $-{ }^{20}$.

\section{Trámite procesal}

a) Competencia: aunque prevalece el criterio de asignarle competencia para entender en el recurso en estudio, al tribunal que oficia de cúspide de la pirámide jurisdiccional respectiva ${ }^{21}$, algunos sostienen que razones prácticas de economía procesal y conexidad aconsejan que entienda en la revisión el mismo juez que dictó la sentencia que se pretende enervar ${ }^{22}$. De la lectura de las diferentes leyes se advierten dos sistemas diferentes de impugnación, a saber: uno que determina que entiende directamente en el recurso el Tribunal Superior de Justicia, como es en Uruguay (SCJ) y en España (Sala de lo Civil del Tribunal Supremo o del Tribunal de Justicia de una Comunidad Autónoma); otro que prevé una demanda autónoma a iniciarse ante el mismo juez o tribunal que dictó la sentencia (San Juan) o ante otro juez (Italia) ${ }^{23}$.

Entendemos como el más apropiado al sistema que aconseja tramitar la demanda autónoma ante otro juez, teniendo en cuenta principalmente que, si bien el fraude habitualmente proviene de las partes o terceros, también puede ser del propio juez o de sus auxiliares.

b) Objeto o motivo de revisión: el objeto final será la revocación del pronunciamiento, en tanto que, inicialmente, deberá investigarse sobre lo sucedido en el proceso cuestionado, verificando si existen

19 Luis Alberto Maurino, op. cit., p. 110.

20 Osvaldo Alfredo Gozaíni. Teoría General del Proceso. Ed. Ediar, 1996, p. 320.

21 Jorge W. Peyrano, op. cit., p. 215.

22 Osvaldo Gozaíni, La conducta en el proceso, p. 279.

23 Roland Arazi, op. cit., p. 385. 
motivos suficientes que habiliten la instancia de revisión y, en especial, si los principios procesales de trascendencia, convalidación, protección, etc., no han operado en el proceso sus papeles definidores y postergan la nueva vía de sustanciación. Si el caso es confuso o dudoso, el magistrado se abstendrá de anular la cosa juzgada ${ }^{24}$. La sentencia que hace lugar a la demanda producirá los efectos que la ley atribuye a la nulidad de los actos jurídicos.

c) Legitimados activos: estarán legitimados para deducir la acción, las partes afectadas, los terceros perjudicados y el Ministerio Público, teniéndose presente cuál ha sido su situación respecto del proceso que se pretende invalidar para deducir de allí si constituye un afectado que no ha sido parte o, si lo ha sido, para concurrir a su respecto los principios citados de convalidación, trascendencia, etc. ${ }^{25}$

d) Prescripción: por aplicación del Art. $4030^{\circ}$ del Código Civil, el plazo de dos años, desde que se toma conocimiento del vicio o desde los momentos indicados en la norma citada, guarda estrecha relación con los tiempos procesales que tampoco toleran la permanencia en los estados de incertidumbre ${ }^{26}$.

e) Potestad cautelar: en principio, la interposición de la demanda no interrumpe el curso de ejecución de la sentencia. En supuestos excepcionales, el tribunal, con caución bastante, puede disponer la suspensión de la ejecución de la sentencia objetada. Un tribunal dispuso, acordando mérito a un pedido cautelar de no innovar, suspender los trámites de ejecución de una sentencia firme mientras pendiese el proceso en que se hizo valer una pretensión de revisión de dicha cosa juzgada ${ }^{27}$.

24 Osvaldo Gozaíni A., op. cit., La conducta en el proceso, p. 279.

25 Osvaldo Gozaíni A., op. cit., La conducta en el proceso, pp. 279-280.

26 Osvaldo Gozaíni A., op. cit., p. 281; en el mismo sentido Jorge W. Peyrano, op. cit., p. 201.

27 Autos: "Género, Jorge Alberto c/Alesso, Nilda Raquel y otros s/Revocación de cosa juzgada", Santa Fe, 28/6/93; ED, 154-424-24. De Midón, Gladis E., "¿Potestad cautelar en la acción de nulidad por cosa juzgada írrita o fraudulenta?", Revista de Derecho Procesal No 1, Ed. Rubinzal Culzoni, 1998, pp. 269-279. 


\section{Conclusiones}

1. Cuando en el proceso median vicios sustanciales intrínsecos parece indudable que la sentencia firme pasada en autoridad de cosa juzgada obtenida en esas condiciones puede ser impugnada mediante una acción autónoma de nulidad ejercida por los terceros perjudicados, por las propias partes o por el Ministerio Público, siempre que se den los requisitos para su viabilidad.

2. Es evidente que en estos casos la presunción de justicia que cubre la decisión pasada en autoridad de cosa juzgada ha de ceder ante la desviación procesal demostrada.

3. No puede invocarse el principio de inmutabilidad de la cosa juzgada cuando no ha existido un auténtico y verdadero proceso judicial.

4. Si bien no existen obstáculos para deducir la revisión de la cosa juzgada resultante de un proceso con escarnio de principios fundamentales, no obstante la circunstancia de que la ley procesal no legisle expresamente sobre el tema, es conveniente que así se lo haga, consagrándose un texto abierto a las situaciones siempre nuevas, a condición de dejar expresamente sentado el carácter excepcionalísimo de dicha acción.

5. En cuanto a la competencia entendemos como el más apropiado al sistema que aconseja tramitar la demanda autónoma ante otro juez, quien sólo podrá suspender la ejecución de la sentencia impugnada en supuestos excepcionales y con caución bastante. 